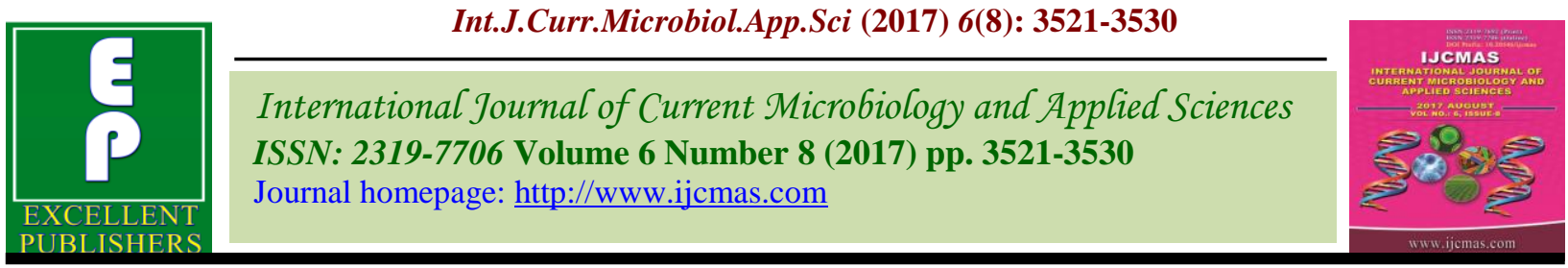

Original Research Article

https://doi.org/10.20546/ijcmas.2017.608.421

\title{
Actinomycetes from Mountains of Hadhramout - Yemen
}

\author{
Ali Mohammed Abdullah Bawazir', Ahmed Al-Haddad', \\ Abdullah AL-Mahdi ${ }^{3}$ and Manjula Shantaram ${ }^{4 *}$ \\ ${ }^{1}$ Department of Microbiology, Mangalore University, Post Graduate Centre, \\ Chikka Aluvara, Kodagu, Karnataka, India \\ ${ }^{2}$ Department of Medical Microbiology, Faculty of Medicine, Hadhramout University, Yemen \\ ${ }^{3}$ Biology Department, Microbiology Division, Faculty of Science, Sana'a University, Yemen \\ ${ }^{4}$ Department of Studies in Biochemistry, Mangalore University, Post Graduate Centre, Chikka \\ Aluvara, Kodagu, Karnataka, India \\ *Corresponding author
}

\section{A B S T R A C T}

\begin{tabular}{|l|}
\hline K e y w o r d s \\
Mountain soils, \\
Actinomycetes, \\
Antibiotic, \\
Antibacterial \\
activity, Starch \\
Casein agar, \\
MKr123/1. \\
\hline Article Info \\
\hline $\begin{array}{l}\text { Accepted: } \\
27 \text { June 2017 } \\
\text { Available Online: } \\
\text { 10 August } 2017\end{array}$ \\
\hline
\end{tabular}

In this study, the soil samples were collected from four different mountain sites of Hadhramout governorate in Yemen to investigate the diversity of actinomycetes. Soil samples were analyzed for physicochemical characteristics (temperature, $\mathrm{pH}$ and nature of the soil samples). Site soil color varied from brown to light brown and dark brown, temperature of the locations ranging from $33^{\circ} \mathrm{C}$ to $39.1^{\circ} \mathrm{C}$ and $\mathrm{pH}$ from 7 to 9 . Actinomycetes were isolated by serial dilution and plating method on starch casein agar media. Total 56 species were isolated on the bases of colony characteristics on starch casein agar and all the isolates were screened for antibacterial activity by agar disk diffusion method (ADD) and agar well diffusion method (AWD). So, 30\% isolates have shown activity against Bacillus subtilis by ADD and 14\% isolates by AWD. For Staphylococcus aureus $24 \%$ isolates had activity by ADD and $8 \%$ isolates had activity by AWD. There were 33\% isolates showing activity against Pseudomonas aeruginosa by ADD and $15 \%$ isolates by AWD. The activity was low against Escherichia coli, only $24 \%$ isolates have shown activity by ADD and $11 \%$ isolates have shown activity by AWD. In this study, we noticed MKr123/1 isolate has a strong activity against both Gram positive and Gram negative bacteria so that MKr123/1 isolate was selected and it is identified as Nocardia otitidiscaviarum.

\section{Introduction}

Hadhramout governorate lies in the eastern part of Yemen. It is comprised of different topography distributed between coastal plains containing beautiful shores on the Arabian Sea, mountains and hills of heights reaching 2000 meters above the sea level. Hot tropical climate in Hadhramout, temperature reaches $40^{\circ} \mathrm{C}$ in summer in the interior areas, where continental dry climate prevails, temperature reaches $36^{\circ} \mathrm{C}$ in the coastal areas, due to seasonal winds saturated with moisture, the temperature in winter tends to be moderate in the coastal areas, $20-24^{\circ} \mathrm{C}$ and $17-20^{\circ} \mathrm{C}$ in the interior areas. Actinomycetes are filamentous, Gram positive bacteria that form branching filaments with hyphae and asexual spores. They were originally incorrectly classified as fungi because they possess true aerial hyphae 
and form spores, both of which are considered to be fungal characteristics (Lechevalier and Lechevalier, 1967). Actinomycetes are one of the most widely distributed groups of microorganisms in nature, forming a large part of the microbial population of the soil and aquatic environment such as rivers, lakes and other freshwater habitats (Good fellow and Williams, 1983). Actinomycetes are currently known to produce over 10,000 bioactive compounds, 7,600 of which have been isolated from streptomycetes and 2,500 from non-streptomycetes, notably from the so called rare actinomycetes (Lazzarini et al., 2000). Growing problem with screening in several years is the difficulty in rediscovery of already known bioactive compounds (Nolan and Cross, 1988). This shows that the easily accessible microorganisms in soil had been exhausted and must search for microorganisms from unknown sources (Igarashi, 2004). One way to address this problem is to expand the source of actinomycetes from other than terrestrial soils. There is also growing interest in the non-streptomycetes actinomycetes as sources of novel compounds (Nolan and Cross, 1988). The study of actinomycetes strains from mountain soils are important because they are an extreme environment which has not been extensively studied but is believed to have a large diversity of organisms that have not yet been discovered. On this basis, it is presumed that the chances of isolating novel actinomycetes from these soils are high.

\section{Materials and Methods}

\section{Soil samples}

Ten soil samples were collected from four mountain sites of different regions of Government Hadhramout - Yemen (Fig.1 \& 2 ). The top layer of soil was removed and taken in sterile polyethylene bags. Samples were air dried at room temperature and then passed through a $0.8 \mathrm{~mm}$ mesh sieve and were preserved in polyethylene bag at room temperature before use. The physical and chemical analyses of the soil samples were carried out by using standard methods (Nawani, 2002) and (Shejul, 1998).

\section{Isolation and culture condition}

For each collection sample, $1 \mathrm{~g}$ of the soil sample was suspended in $10 \mathrm{ml}$ and plated on Starch Casein Agar (SCA, pH 7). The inoculated plates were incubated for 2 weeks at $37^{\circ} \mathrm{C}$. The suspected colonies for actinomycetes were selectively isolated and transferred to SCA with the help of loop inoculum method. (Kanavade, 2003). Morphology and color of the $\mathrm{MKr}$ colony isolate was determined by inoculating on different media and incubated at $28^{\circ} \mathrm{C}$ for 21 days (Table 1) (Shirling and Gottlieb, 1972). And diffusible pigmentation was determined on glycerol asparagine agar (GAA) and tyrosine agar (TA) for melanin pigment formation. Isolates were inoculated at $28^{\circ} \mathrm{C}$ for 21 days and observed formation of pigment (Williams and Wellington, 1982a).Morphological characters of the $\mathrm{MKr}$ isolate was grown on following media: (1) Starch Casein Agar (SCA) (Nawani, 2002), (2) Glycerol Asparagine Agar (GAA) (Kanavade, 2003), (3) Nutrient Agar (NA) (Goodfelow and O'Donnel, 1989), (4) Yeast extract -Malt extract Agar (YMA), (5) Czapeck's Dox-Thom Agar (CDTA) (Collins et al., 1995) and (6) Sabouraud's Dextrose Agar (SDA) of $\mathrm{pH}$ 7.0. The inoculated plates were incubated at $28^{\circ} \mathrm{C}$ for $7-14$ days and observed for colony characters, sporulation and pigmentation (Holt et al., 1994).

\section{Screening of antimicriobial activity}

All actinomycetes isolates were screened for their antimicrobial activity by two techniques: agar disc diffusion method (ADD) and agar well diffusion method (AWD). The target bacterial cultures used were Escherichia coli, 
Staphylococcus aureus, Bacillus subtilis and Pseudomonas aeruginosa (Pisano et al., 1992). Based on their antimicrobial properties, isolates were chosen for further biochemical and morphological characterization.

\section{Characterization of actinomycetes}

The strong actinomycetes isolates selected from screening were characterized by morphological, biochemical and physiological methods. The morphological method consists of macroscopic and microscopic characterization (Kawato and Sinobu 1979). Various biochemical tests performed were activity of catalase and oxidase, carbon source utilization, nitrate reduction, starch hydrolysis, urea hydrolysis, gelatin hydrolysis and the physiological tests included motility, $\mathrm{NaCl}$ resistance, temperature tolerance and $\mathrm{pH}$ tolerance.

\section{Results and Discussion}

Soil samples collected from mountains had varied $\mathrm{pH}$, temperature and soil color (Table 1). The present study clearly indicated that physico-chemical parameters influenced the biodiversity and distribution of actinobacteria in some mountain Hadhramout Yemen. Same observation was made by a scientist, who found that the distribution of actinobacteria was influenced by physico-chemical parameters such as the soil color, $\mathrm{pH}$ and temperature which were noted to influence the growth rate of microorganisms (AlMahdi, 2005). From 56 actinomycete isolates, 19 isolates were selected for the study according to color and their activity against bacterial pathogens (Fig.3). All the isolates were screened for antimicrobial activity, by ADD and AWD. Antimicrobial activity was studied against Gram negative and Gram positive bacteria. The target cultures used were E. coli, $P$. aeruginosa. S. aureus, and $B$. subtilis. Out of 56 actinomycete isolates, there were $30 \%$ isolates showing activity against $B$. subtilis by ADD and $14 \%$ isolates by AWD. For $S$. aureus $24 \%$ isolates had activity by ADD and $8 \%$ isolates had activity by AWD. There were $33 \%$ isolates showing activity against $P$. aeruginosa by ADD and $8 \%$ isolates by AWD. The activity was low against Escherichia coli, only $24 \%$ isolates showed activity by ADD and $11 \%$ isolates showed activity by AWD as shown in Fig.4. The ADD method used for screening antibacterial was more effective and gave better results than AWD as shown in Fig.5. Similar results were reported by, ALMekhlafi (2007), who found the activity in liquid media decreased in comparison with that shown by the method of agar blocks. Frequency of occurrence of actinomycetes with their $\mathrm{pH}$ and temperature is shown in table 1. For B. subtilis the maximum inhibition zone diameter was $28 \mathrm{~mm}$ by ADD technique but by AWD the zone was $15 \mathrm{~mm}$. For $S$. aureus the maximum inhibition zone was $26 \mathrm{~mm}$ by ADD technique and $12 \mathrm{~mm}$ by AWD. For $E$. coli the maximum inhibition zone diameter was $24 \mathrm{~mm}$ by ADD technique, but was $14 \mathrm{~mm}$ by AWD. The inhibition zone of $P$. aeruginosa was $27 \mathrm{~mm}$ by ADD, but was $13 \mathrm{~mm}$ by AWD (Fig.6).

In this study, we noticed MKr123/1 isolate had strong activity against both Gram-positive and Gram-negative bacteria, so MKr123/1 isolate was selected for other studies (Fig.7). Our isolated strain was identified based on their colony morphology and microscopic morphology (Table 2). The mycelium structure, color, and arrangement of spore were observed by cover slip technique. Similar method has been followed by Berd (1973) and Mansour (2003). In this study, MKr12/1 was taxonomy based on the morphological, physiological and biochemical properties (Tables 3-5 \&7) according to Waksman (1953) and Long (1994). 
Fig.1 Map of the sample regions

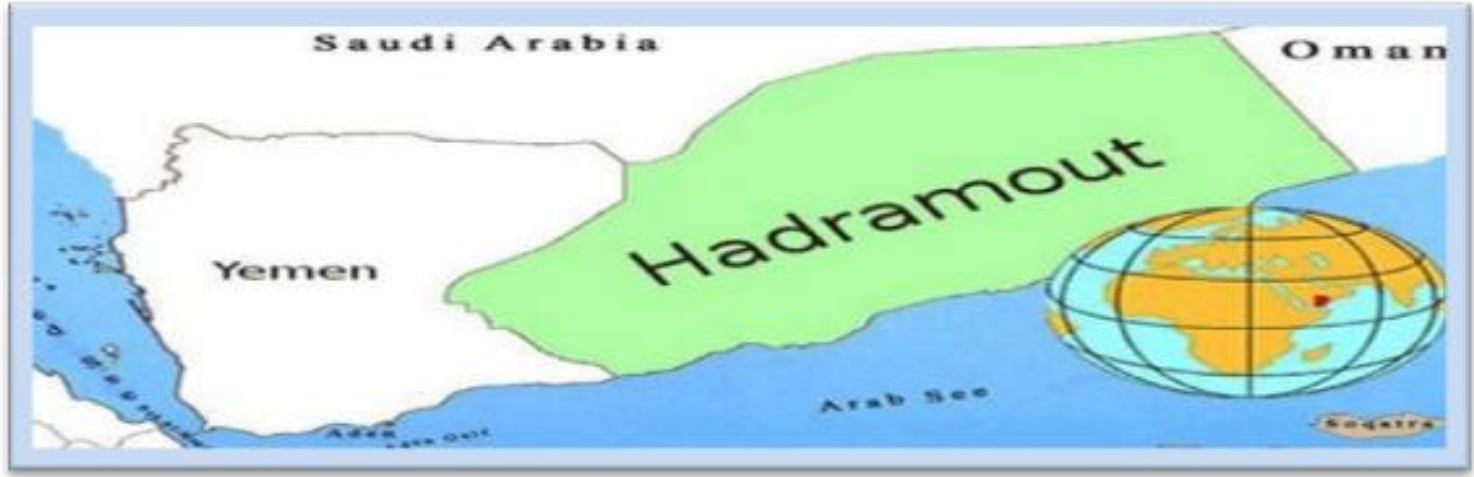

Fig.2 Hadhramout sample sites

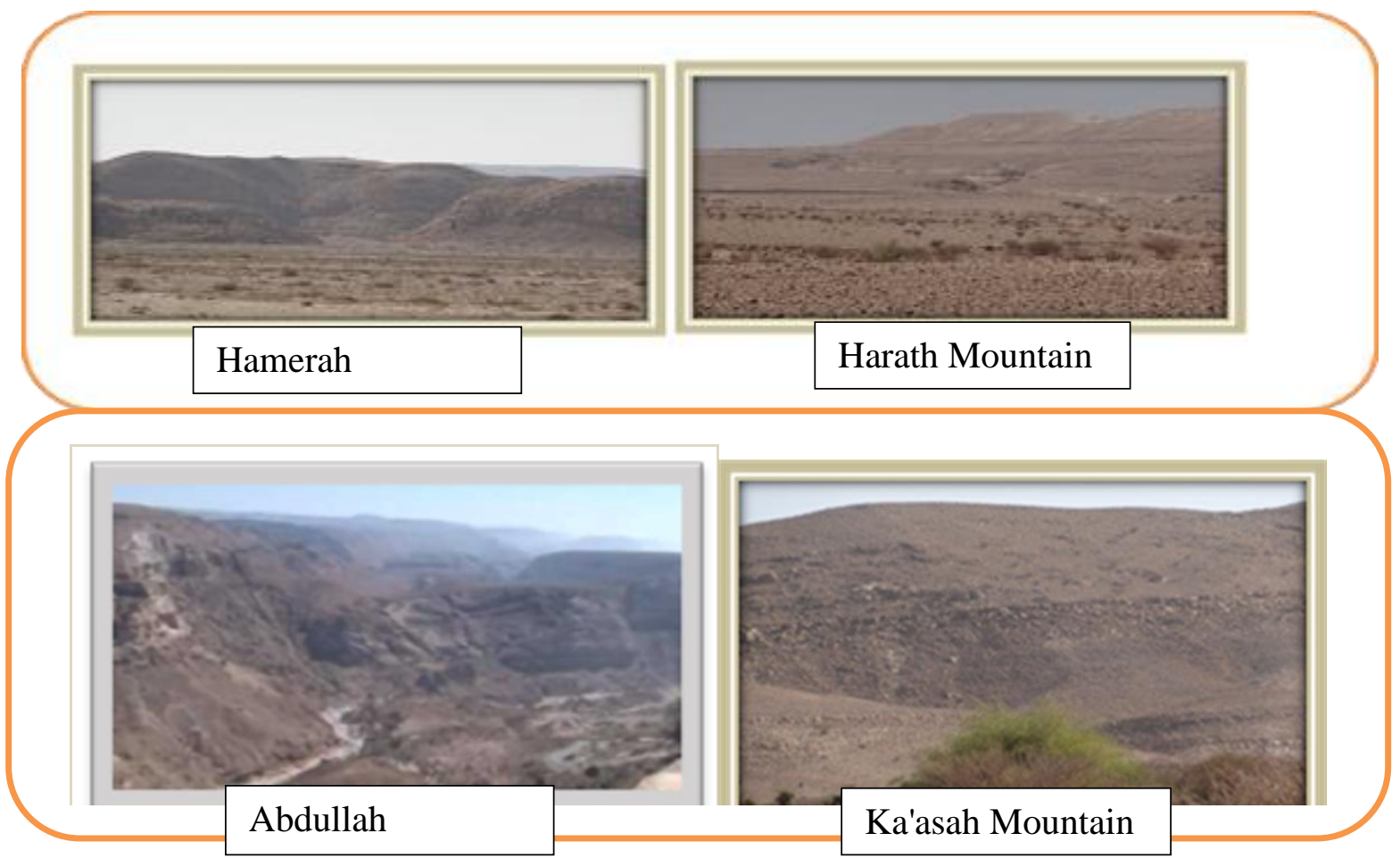

Fig.3 Selection of actionmycetes from different soils

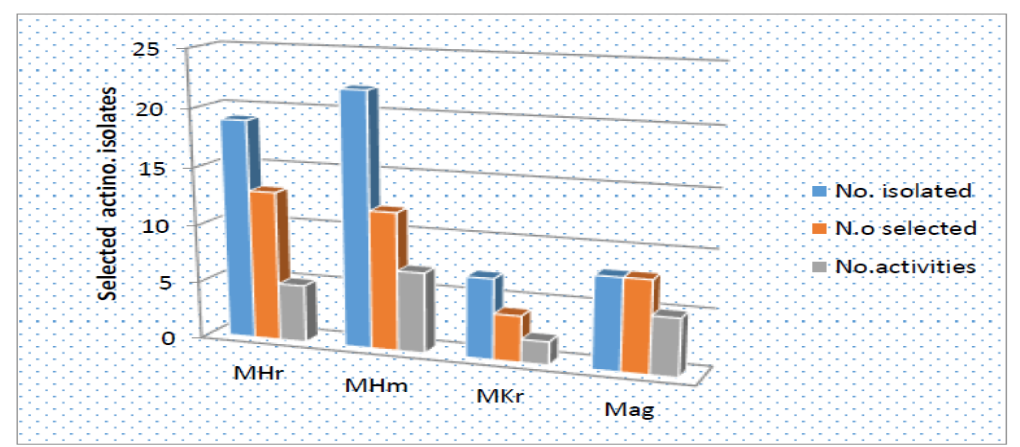


Fig.4 Percentage of antibacterial activity of actinomycete isolates

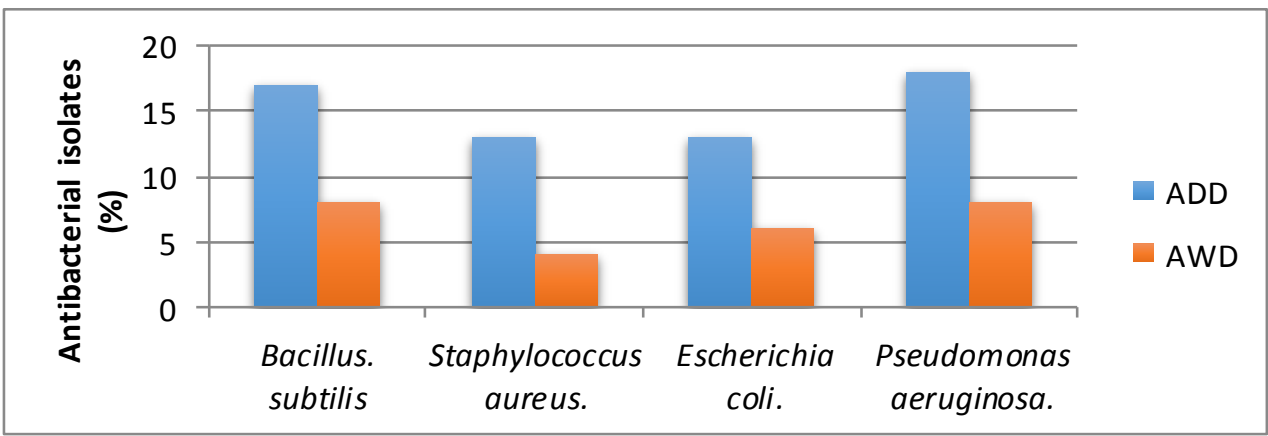

Fig.5 Maximum inhibition zone of antibacterial activity of actinomycete isolates by (ADD) and (AWD)

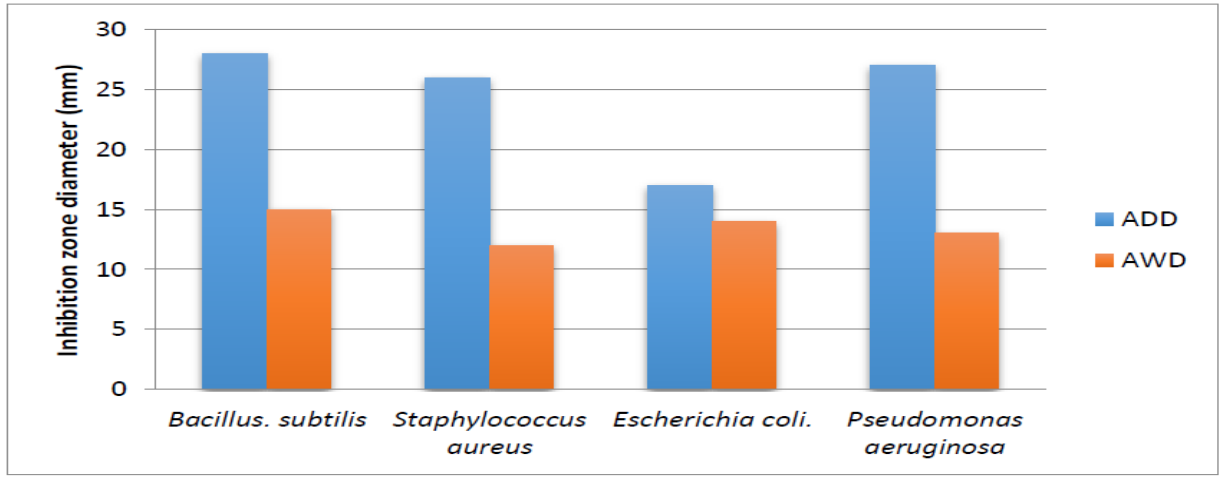

Fig.6 Antibacterial activity by ADD and AWD method

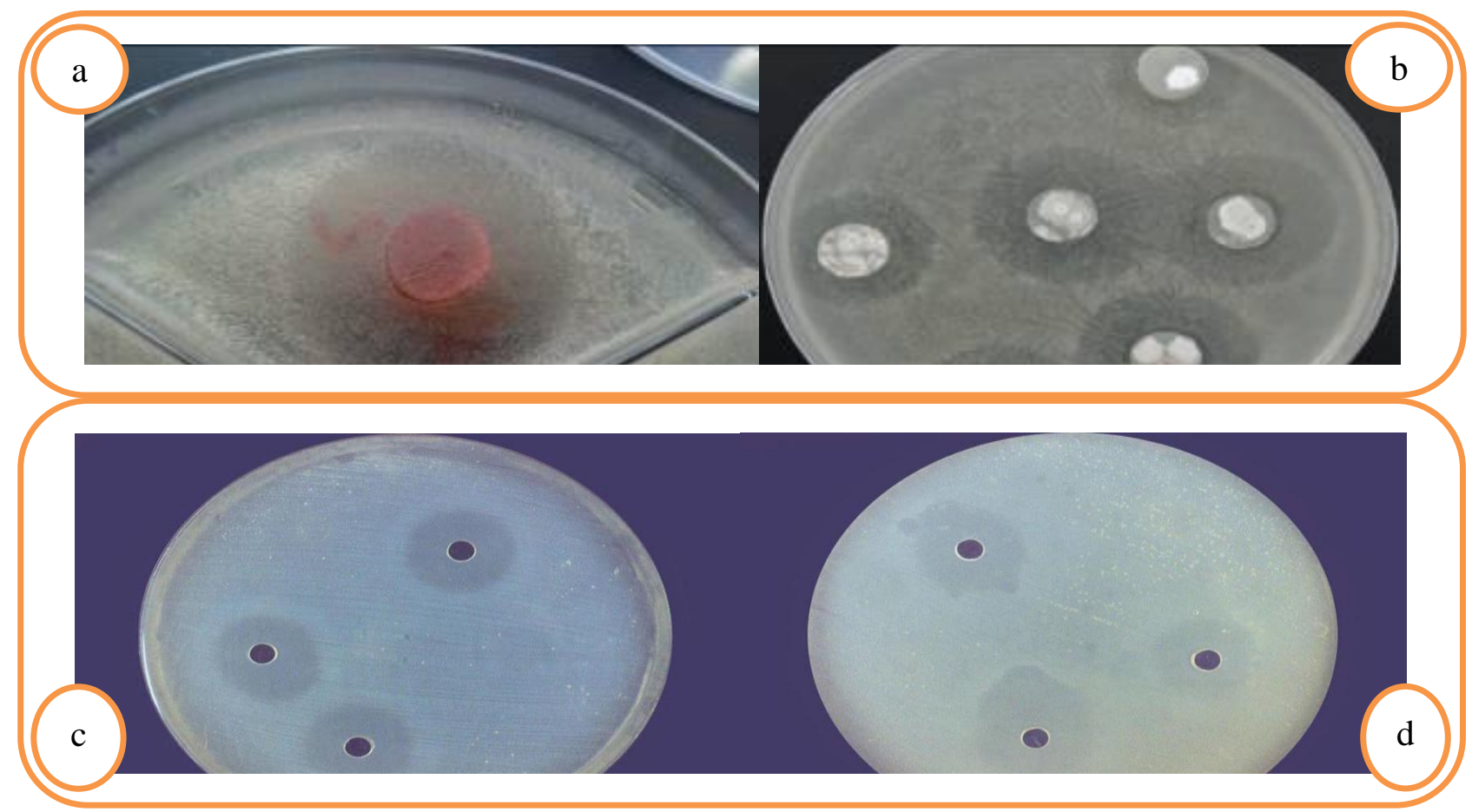


Int.J.Curr.Microbiol.App.Sci (2017) 6(8): 3521-3530

Fig.7 Colony and spore morphology of MKr12/1isolate

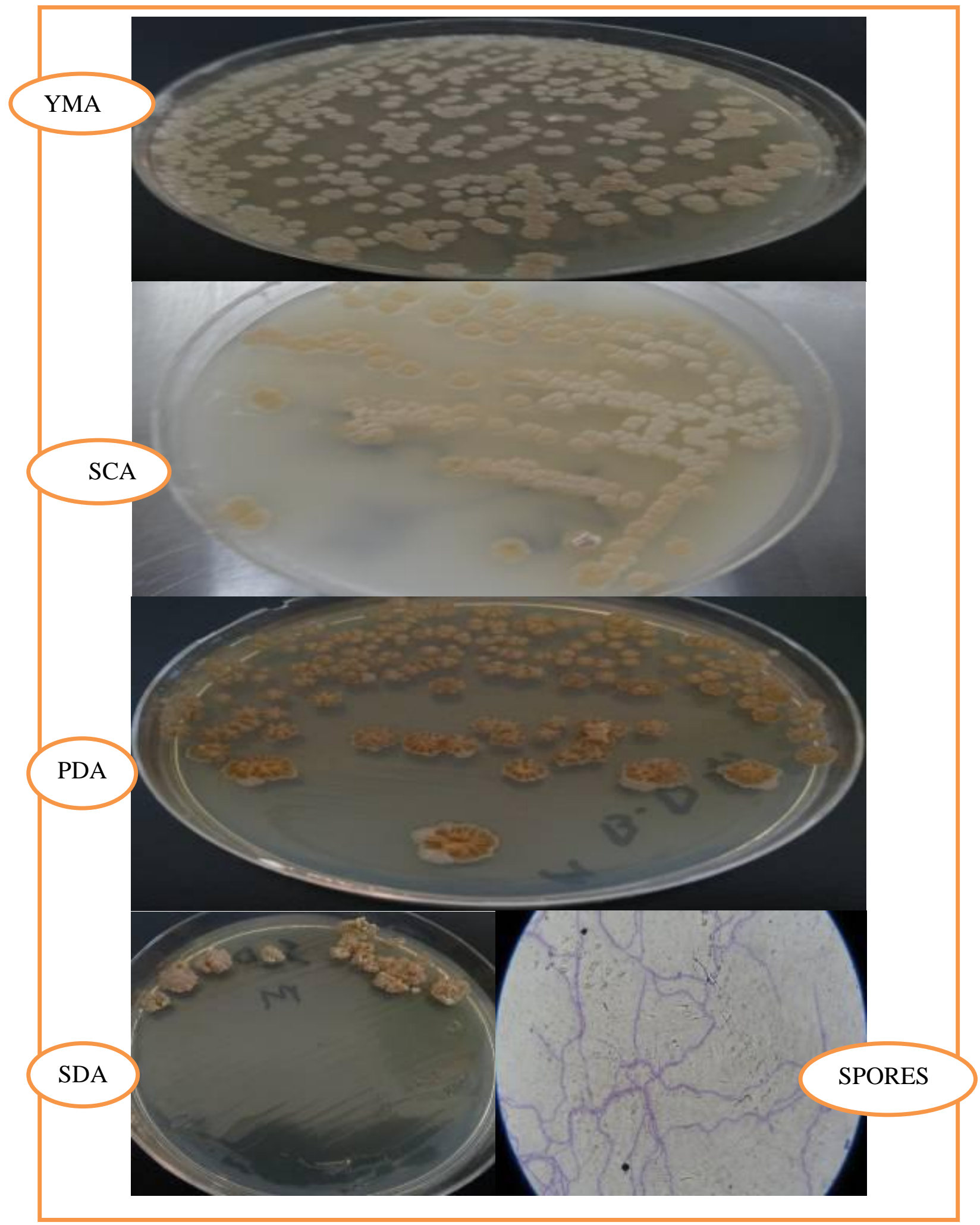


Table.1 Frequency of occurrence of actinomycetes and their $\mathrm{pH}$ and temperature

\begin{tabular}{|c|c|c|c|c|c|}
\hline Organism name & Color & Source & Location & $\mathrm{pH}$ & Temperature ${ }^{\circ} \mathrm{C}$ \\
\hline $\mathrm{MHr}$ & Brown & Hadhramout & Harass & 9.0 & 39.1 \\
\hline $\mathrm{Mag}$ & Light brown & Hadhramout & RasHawara & 7.9 & 29.0 \\
\hline $\mathrm{MHm}$ & Dark brown & Hadhramout & Hamerah & 7.9 & 33.0 \\
\hline $\mathrm{MKr}$ & Light brown & Hadhramout & Ka'asah & 8.3 & 33.5 \\
\hline
\end{tabular}

Table.2 Spore and colony morphology of actinomycete isolates

\begin{tabular}{|c|c|c|c|c|}
\hline Colony Characters & Colony shape & Colony consistency & Colony elevation & Time of Colony Visible \\
\hline \multirow{3}{*}{ MKr12/1 } & Irregular & Hard & Convex & 48 hrs. \\
\cline { 2 - 5 } & Spore Grouping & Spore motility & Spore color & Spore Chain \\
\cline { 2 - 5 } & Chain & Non motile & Beige & Spiral \\
\hline
\end{tabular}

Table.3 Growth and cultural characteristics of MKr12/1 on different media

\begin{tabular}{lllll}
\hline Culture medium & Growth & Arial mycelium & Substrate mycelium & Soluble pigment \\
\hline Starch casein agar & Moderate & None & Beige & None \\
Nutrient agar & Poor & None & Beige & None \\
Sabouraud dextrose agar & Poor & None & Saffron yellow & None \\
Potato dextrose agar & Good & None & Orange brown & Pale brown \\
Yeast- malt extract agar & Good & None & Maize yellow & None \\
Glycerol- asparagine agar & Moderate & White yellow & Cream & None \\
Tyrosine agar & Good & White & Orange brown & Brown \\
Czapeck's -dox- thom agar & Moderate & None & Cream & None \\
Glycerol yeast extract agar & Good & None & Beige & None \\
Starch yeast extract agar & Good & None & Yellow orange & None \\
\hline
\end{tabular}

Table.4 Physiological characters of MKr12/1isolate

\begin{tabular}{|c|c|}
\hline Physiological characters & MKr12/1 \\
\hline \multicolumn{2}{|l|}{ Temperature: } \\
\hline $20^{\circ} \mathrm{C}$. & + \\
\hline $28^{\circ} \mathrm{C}$. & + \\
\hline $37^{\circ} \mathrm{C}$. & + \\
\hline $45^{\circ} \mathrm{C}$. & - \\
\hline $60{ }^{\circ} \mathrm{C}$. & - \\
\hline \multicolumn{2}{|l|}{$\mathrm{pH}:$} \\
\hline 3.5 & - \\
\hline 4.5 & + \\
\hline 7.0 & + \\
\hline 10.0 & + \\
\hline \multicolumn{2}{|l|}{$\mathrm{NaCl}$ Tolerance: } \\
\hline $0 \%$ & + \\
\hline $2 \%$ & + \\
\hline $4 \%$ & + \\
\hline $6 \%$ & + \\
\hline $8 \%$ & + \\
\hline $10 \%$ & \\
\hline
\end{tabular}

+ Growth; - No growth 
Table.5 Sensitivity of actinomycete isolates to antibiotics (zone of inhibition $\mathrm{mm}$ )

\begin{tabular}{|c|c|}
\hline Antibiotic & MKr12/1 (mm) \\
\hline Gentamicin $(10 \mu \mathrm{g})$ & 28 \\
\hline Amphotericin B $(100 \mu \mathrm{g})$ & + \\
\hline Flucanazole $(10 \mu \mathrm{g})$ & + \\
\hline Novobiocin $(30 \mu \mathrm{g})$ & 30 \\
\hline Penicillin $\mathrm{G}(10 \mu \mathrm{g})$ & 40 \\
\hline Nystatin $(10 \mu \mathrm{g})$ & + \\
\hline Clotrimazol $(10 \mu \mathrm{g})$ & 38 \\
\hline Co-trimazole $(25 \mu \mathrm{g})$ & 10 \\
\hline Tetracycline $(30 \mu \mathrm{g})$ & 28 \\
\hline
\end{tabular}

Table.6 Results showing utilization of carbon and nitrogen sources

\begin{tabular}{|c|c|}
\hline Utilized carbon source & MKr12/1 \\
\hline D- Glucose & +++ \\
\hline Citric acid & \pm \\
\hline Lactic acid & \pm \\
\hline Cellulose & +++ \\
\hline Lactose & +++ \\
\hline Dextrose & +++ \\
\hline D- Mannose & +++ \\
\hline D- Fructose & ++ \\
\hline Sucrose & +++ \\
\hline L- Arabinose & +++ \\
\hline D- Mannitol & +++ \\
\hline Sodium acetate & + \\
\hline Starch & +++ \\
\hline Glycerol & ++ \\
\hline D- Maltose & +++ \\
\hline Basal medium & + \\
\hline \multicolumn{2}{|c|}{ Nitrogen source } \\
\hline L-Asparagine & +++ \\
\hline L-Tyrosine & + \\
\hline Glycine & + \\
\hline Ammonium sulphate & +++ \\
\hline Sodium nitrate & +++ \\
\hline Basal medium & + \\
\hline $\mathrm{H}_{2} \mathrm{~S}$ production & - \\
\hline Acid fast reaction & + \\
\hline
\end{tabular}

+++: Very good; ++: Good; +: Poorly; -: Negative; t: Moderate 
Table.7 Enzyme activity of actinomycete isolates

\begin{tabular}{|cc|}
\hline Enzymes & MKr12/1 \\
\hline \hline Amylase & - \\
Caseinase & - \\
Catalase & + \\
Chitinase & + \\
Gelatinase & - \\
Keratinase & + \\
Lecithinase & + \\
Lipase & - \\
Pectinase & - \\
DNase & + \\
Urase & + \\
\hline +: Positive test; - : Negative test
\end{tabular}

So, the MKr was identified as Nocardia otitidiscaviarum. Substrate mycelium was colorless and aerial mycelium form short spore chains. The spore mass was yellow to orange. Diffusible pigment was produced. The isolates tolerated 5\% $\mathrm{NaCl}$. The isolates utilized chitin, keratin, pectin and cellulose. The isolates utilized mannose, fructose and mannitol as carbon sources (Table 6).

Distribution of actinobacteria was influenced by physico-chemical parameters such as the soil type, soil color, $\mathrm{pH}$ and temperature. So, an attempt was made to expand the source of actinomycetes by carrying out ecological assessments of environments other than terrestrial soils. The agar disc diffusion method was more effective for antibacterial activity than agar well diffusion method against bacterial pathogen because liquid medium is fragmented into rods and cell morphology plays an important role in the production of antibiotics. Starch casein medium was the best media for production of antibiotics at $\mathrm{pH} 7$.

\section{Acknowledgement}

First of all, we would like to express great thanks to the grandeur Allahfor his generous help, kindness and mercy during the whole of my life in general and for accomplishing this work specifically. Our special thanks to everyone in National Center for Central Public Health Laboratories-Hadhramout Branch, for their endless assistance. Last but not the least, we take great pleasure in expressing thanks to our parents and friends who helped us a lot in finishing the project that made us indeed successful.

\section{References}

Al-Mahdi, A.Y., 2005. Isolation and identification of antibiotic production acidophilic actinomycetes, University of Pune, Pune, India.

Al-Mekhlafi, N.A., 2007. Bioactivity effect of some actinomycete isolates on some pathogenic microorganisms, University of Sana'a, Faculty of Science, Yemen.

Berd, D., 1973. Laboratory identification of clinically important aerobic actinomycetes. Appl. Microbiol. 25, 665-681.

Collins, C.H., Lyne, P. M. and Granje, J. M. 1995. Microbiological Methods. Butterworth and Heinemann publishers. Goodfellow, M., and O'Donnell, A. G. 1989. Search and discovery of industrialysignificant actinomycetes. In Microbial Products: New Approach, pp. 343-383. Edited by S. Baumberg, I. S. Hunter \& 
P. M. Rhodes. Cambridge, UK:

Cambridge University Press.

Goodfellow, M., and Williams, S. T. 1983.

Ecology of actinomycetes. Ann. Rev.

Microbiiol. 37; 189-216.Ph.d. thesis

Department of Microbiology, University of Pune, India.

Holt, J.G., Krieg, N. R. Sneath, P. H. A. Staley, J. T. and Williams, S. T. 1994. Other genera. In: Bergey's Manual of Systematic Bacteriology, 9, 701-703. Williams and Wilkins, Baltimore.

Igarashi, Y., 2004. Screening of novel bioactive compounds from plantassociated actinomycetes. Actinomycetol. 18; 63-66.

Kanavade, V.L., 2003. Use of Bio-Industrial Waste for Production of Microbial Biomass with Potential in Environmental Management. Ph.D. Thesis, University of Pune, India.

Kawato, M., Shinobu, R., 1959. A simple technique for the microscopical observation, memoirs of the OsakaUniversity Liberal Arts and Education, 114

Lazzarini, A., Cavaletti, L. Toppo, G. and Marinelli, F. 2000. Rare genera of actinomycetes as potential producers of new antibiotics. Antonie van Leeuwenhoek 78, 399-405

Lechevalier, H. A., and Lechevalier, M.P. 1967. Biology of actinomycetes. Ann Rev Microbial. 21: 71-99.

Long, P.F., 1994. Identification of some industrially important Actioplanesspecies. Journal Industrial Microbiology. 13, 300-310.
Mansour, S.R., 2003. The occurrence and distribution of soil actinomycetes in Saint Catherine area, South Sinai, Egypt. Pak. J. Biol. Scienc., 6: 721-728.

Nawani, N.N., 2002. Diversity of chitinases of bacterial origin. Ph.D. Thesis. University of Pune. Pune. India.

Nolan, R.D., and Cross, T. 1988. In "Actinomycetes in Biotechnology" (Goodfellow, M. Williams, S. T. and Mordarski, M. Eds.), pp. 1-32. Academic Press. London.

Pisano, M.A., Sommer, M. J. and Taras, L. 1992. Bioactivity of chitinolytic actinomycetes of marine origin. Appl. Microbiol. Biotechnol, 36; 553-555.

Shejul, M.S., 1998. Studies on Heterotrophic Filamentous Procaryotes from Aquatic Habitats. Ph.D. Thesis, University of Pune, India.

Shirling, E. B. and Gottlieb, D. (1972). Cooperative description of type strains of Streptomyces V. Additional descriptions. Int J SystBacteriol. 22; 265-394.

Waksman, S.A., 1953. The Actinomycetes. 1 st edition, Watham, MASS, USA.

Williams, S.T., and Wellington, E. M. H. 1982a. Actinomycetes, Ch. In: Methods of Soil analysis. Part 2. Chemical and Microbiological Properties. 2nd edit. (Page, A. I. Miller, R. H. and Keeney, D. R. Eds.). Amer. Soc. Agronomy Soil Science Soc. America Inc. Pub. Madison, Wisconsin, USA. 45; 969987.

\section{How to cite this article:}

Ali Mohammed Abdullah Bawazir, Ahmed Al-Haddad, Abdullah AL-Mahdi and Manjula Shantaram. 2017. Actinomycetes from Mountains of Hadhramout - Yemen. Int.J.Curr.Microbiol.App.Sci. 6(8): 3521-3530. doi: https://doi.org/10.20546/ijcmas.2017.608.421 